\title{
Global best approximate solutions for set-valued cyclic $\alpha$-F-contractions
}

\author{
Nawab Hussain ${ }^{\mathrm{a}}$, Iram Iqbal,** \\ ${ }^{a}$ Department of Mathematics, King Abdulaziz University, P. O. Box 80203, Jeddah 21589, Saudi Arabia. \\ ${ }^{b}$ Department of Mathematics, University of Sargodha, Sargodha, Pakistan.
}

Communicated by M. Eslamian

\begin{abstract}
In this paper, we introduce the concepts of multivalued cyclic $\alpha$-F contraction and triangular $\alpha$-orbital admissible mappings. We use these concepts to find global best approximation solutions in a metric space with proximally complete property. We also provide some nontrivial examples to support our results. As an application, we obtain best proximity point results in partially ordered metric spaces and best proximity point theorems for single-valued mappings. We also prove fixed point results for multivalued and single-valued $\alpha$-type F-contractions. (C)2017 All rights reserved.
\end{abstract}

Keywords: Proximally complete pair, cyclic $\alpha$-F-contraction, cyclical Cauchy sequence, best proximity point. 2010 MSC: 46N40, 47H10, 54H25, 46T99

\section{Introduction and preliminaries}

Let $(X, \mathrm{~d})$ be a metric space. $2^{X}$ denotes the family of all nonempty subsets of $X, \mathrm{C}(X)$ denotes the family of all nonempty, closed subsets of $X, \mathrm{CB}(X)$ denotes the family of all nonempty, closed, and bounded subsets of $X$, and $\mathrm{K}(X)$ denotes the family of all nonempty compact subsets of $X$. It is clear that, $\mathrm{K}(X) \subseteq \mathrm{CB}(X) \subseteq \mathrm{C}(X) \subseteq \mathrm{P}(X)$. For $\mathrm{A}, \mathrm{B} \in \mathrm{C}(X)$, let

$$
H(A, B)=\max \left\{\sup _{x \in A} D(x, B), \sup _{y \in B} D(y, A)\right\},
$$

where $D(x, B)=\inf \{d(x, y): y \in B\}$. Then $H$ is called generalized Pompeiu Hausdorff distance on $C(X)$. It is well-known that $\mathrm{H}$ is a metric on $\mathrm{CB}(X)$, which is called Pompeiu Hausdorff metric induced by $\mathrm{d}$. For detail see $([4,12,29])$. Define $d^{*}(x, y)=d(x, y)-\operatorname{dist}(A, B), D^{*}(x, B)=D(x, B)-\operatorname{dist}(A, B)$, and $H^{*}(A, B)=H(A, B)-\operatorname{dist}(A, B)$, where

$$
\operatorname{dist}(A, B)=\inf \{d(x, y): x \in A, y \in B\} .
$$

Observe that if $\mathrm{C} \subseteq \mathrm{B}$, then $\mathrm{D}(\mathrm{x}, \mathrm{B}) \leqslant \mathrm{D}(\mathrm{x}, \mathrm{C})$ for all $x \in \mathcal{X}$. This implies

$$
\operatorname{dist}(A, B) \leqslant D(a, C), \quad \forall a \in A .
$$

\footnotetext{
*Corresponding author

Email addresses: nhusain@kau .edu.sa (Nawab Hussain), irami@uos .edu.pk (Iram Iqbal)
} 
In fixed point theorems, we find a solution of the equation $\mathcal{T} x=x$, where $\mathcal{T}$ is a self-mapping on a subset $A$ of a metric space $X$. However, a mapping $\mathcal{T}: A \rightarrow B$, where $A$ and $B$ are disjoint subset of $X$ and $\mathcal{T}$ is a mapping sending $A$ into $B$ and $B$ into $A$; the aforementioned equation does not necessarily has a solution. Then one can determine an element $x \in A$ in the sense that the distance $d(x, \mathcal{T} x)$ is minimum. A best approximation theorem introduced by Fan [18] asserts that if $\mathrm{K}$ is a nonempty compact and convex subset of a normed space $X$ and $\mathcal{T}: K \rightarrow X$ is a continuous mapping, then there exists an element $X$ satisfying the condition $d(x, \mathcal{T} x)=\inf \|y-\mathcal{T} x\|, y \in K$. A best approximation theorem guarantees the existence of an approximate solution, while a best proximity point theorem provides the possibility of finding an approximate solution which is optimal in the sense that there exists an element $x$ such that $d(x, \mathcal{T} x)=\operatorname{dist}(A, B)$; the element $x$ is called a best proximity point of $\mathcal{T}$. If $\mathcal{T}: A \rightarrow C B(B)$ is a multivalued mapping, then $x \in A$ satisfying $D(x, \mathcal{T} x)=\operatorname{dist}(A, B)$ is called a best proximity point of $\mathcal{T}$. The existence of best proximity points is an interesting aspect of optimization theory and it has attracted the attention of many authors (see $[1,2,6,8,16,24,42]$ and references therein). Moreover, best proximity point theorems for several classes of multivalued mappings have been proved in $[3,11,15,19,46]$.

In 2012, Samet et al. [41] defined $\alpha$-admissible mappings and established fixed point theorems. After this, Popescu [37] proposed the concept of $\alpha$-orbital admissible and triangular $\alpha$-orbital admissible.

Definition 1.1 ([37]). Let $\mathcal{T}: X \rightarrow X$ be a mapping and $\alpha: X \times X \rightarrow[0, \infty)$ be a function, then $\mathcal{T}$ is said to be $\alpha$-orbital admissible if

$$
\alpha(z, \mathcal{T} z) \geqslant 1 \text { implies that } \alpha\left(\mathcal{T} z, \mathcal{T}^{2} z\right) \geqslant 1, \quad z \in X
$$

Moreover, $\mathcal{T}$ is called a triangular $\alpha$-orbital admissible if $\mathcal{T}$ is $\alpha$-orbital admissible and

$$
\alpha(z, y) \geqslant 1 \text { and } \alpha(y, \mathcal{T} y) \geqslant 1 \text { implies that } \alpha(z, \mathcal{T} y) \geqslant 1, \quad z, y \in X
$$

Note that each $\alpha$-admissible (triangular $\alpha$-admissible) mapping is an $\alpha$-orbital admissible (triangular $\alpha$-orbital admissible). For examples and details in this direction see [22, 30, 37, 40].

On the other hand Asl et al. [9] extended concept of $\alpha$-admissible mapping to multivalued mappings.

Definition 1.2 ([26]). Let $\mathcal{T}: X \rightarrow 2^{X}$ be a multivalued map on metric space $(X, d)$, and $\alpha: X \times X \rightarrow[0, \infty)$ be a function, then $\mathcal{T}$ is an $\alpha_{*}$-admissible mapping if

$$
\alpha(y, z) \geqslant 1 \text { implies that } \alpha_{*}(\mathcal{T} y, \mathcal{T} z) \geqslant 1, \quad y, z \in X,
$$

where

$$
\alpha_{*}(\mathcal{A}, \mathcal{B})=\inf _{y \in \mathcal{A}, z \in \mathcal{B}} \alpha(y, z) .
$$

Further, Ali et al [5] generalized the Definition 1.2 in the following way:

Definition 1.3 ([5]). Let $\mathcal{T}: X \rightarrow 2^{X}$ be a multivalued map on metric space $(X, d)$ and $\alpha: X \times X \rightarrow[0, \infty)$ be a function. We say that $\mathcal{T}$ is generalized $\alpha_{*}$-admissible mapping if

$$
\alpha(y, z) \geqslant 1 \text { implies that } \alpha(u, v) \geqslant 1 \text { for all } u \in T y, v \in T z \text {. }
$$

One of the interesting generalization of the Banach contraction principle is given by Wardowski [44], he defined $\mathcal{F}$-contraction and proved fixed point results for these contractions. Many authors did work in this direction (see $[7,23,25,28,35,45]$ and references therein). Following Wardowski, we denote by $\mathcal{F}$, the set of all functions $\mathrm{F}: \mathbb{R}^{+} \rightarrow \mathbb{R}$ satisfying following conditions:

(F1) F is strictly increasing;

(F2) for all sequences $\left\{\alpha_{n}\right\} \subseteq \mathbb{R}^{+}, \lim _{n \rightarrow \infty} \alpha_{n}=0$ if and only if $\lim _{n \rightarrow \infty} F\left(\alpha_{n}\right)=-\infty$; 
(F3) there exists $0<k<1$ such that $\lim _{\alpha \rightarrow 0^{+}} \alpha^{k} F(\alpha)=0$.

Definition 1.4 ([44]). A mapping $T: X \rightarrow X$ is said to be an F-contraction if there exist $F \in \mathcal{F}$ and $\tau>0$ such that for all $x, y \in X$

$$
d(T x, T y)>0 \quad \text { implies that } F(d(T x, T y)) \leqslant F(d(x, y)) .
$$

Theorem 1.5 ([44]). Let $(\mathrm{X}, \mathrm{d})$ be a complete metric space and let $\mathrm{T}: \mathrm{X} \rightarrow \mathrm{X}$ be an $\mathrm{F}$-contraction. Then $\mathrm{T}$ has a unique fixed point in $\mathrm{X}$.

Note that, in general, $\mathrm{F}$ is not continuous. However, by (F1) and the properties of the monotone functions, we have the following proposition.

Proposition 1.6 ([43]). Let $\mathrm{F}: \mathbb{R}^{+} \rightarrow \mathbb{R}$ be a function satisfying (F1) and (F2), then there exists a countable subset $\Delta(\mathrm{F}) \subseteq(0, \infty)$ such that

$$
\mathrm{F}(\mathrm{t}-0)=\mathrm{F}(\mathrm{t})=\mathrm{F}(\mathrm{t}+0) \quad \text { for each } \mathrm{t} \in(0, \infty) \backslash \Delta(\mathrm{F}) .
$$

Turinici [43] also replaced condition (F2) by the following:

$\left(\mathrm{F} 2^{*}\right) \mathrm{F}(\mathrm{t}) \rightarrow-\infty$ when $\mathrm{t} \rightarrow 0^{+}$,

and gave the following lemma:

Lemma 1.7 ([43]). Let $\mathrm{F}: \mathbb{R}^{+} \rightarrow \mathbb{R}$ be a function satisfying $(\mathrm{F} 1)$ and $(\mathrm{F} 2 *)$. Then for each sequence $\left\{\mathrm{t}_{\mathrm{n}}\right\}$ in $(0, \infty)$

$$
\mathrm{F}\left(\mathrm{t}_{\mathrm{n}}\right) \rightarrow-\infty \Rightarrow \mathrm{t}_{\mathrm{n}} \rightarrow 0 .
$$

Denote by $\mathfrak{F}$, the collection of functions $\mathrm{F}: \mathbb{R}^{+} \rightarrow \mathbb{R}$ satisfying (F1) and (F2*).

Very recently, Imdad et al. [27] observed that in proofs of the results on $\alpha$-type F-contractions (for example, [20,36]), the authors assumed that $F(s) \leqslant \alpha(x, y) F(s)$, for $\alpha(x, y) \geqslant 1$, which is not true in general as $\mathrm{F}$ may have negative values.

Continuing in this direction, we introduce multivalued cyclic $\alpha$-F-contraction and use it to obtain best proximity points with proximally complete property. It is considered as a global optimization problem, which seeks a solution by finding the best approximation solution of a fixed point inclusion. We also overcome the error mentioned by Imdad et al. [27] and prove fixed point results for $\alpha$-type F-contractions.

The following definitions and lemmas will be used in the sequel.

Definition $1.8([17])$. A pair $(A, B)$ of non-empty subsets of metric space $(X, d)$ is said to be sharp proximal if for each $x \in A$ and $y \in B$, there exists a unique $x^{\prime} \in B$ and $y^{\prime} \in A$ such that

$$
d\left(x, x^{\prime}\right)=d\left(y, y^{\prime}\right)=\operatorname{dist}(A, B) .
$$

Definition 1.9 ([17]). A pair $(A, B)$ of non-empty subsets of metric space $(X, d)$ is said to be semi-sharp proximal if for each $x \in A$ and $y \in B$, there exists at most one point $x^{\prime} \in B$ and $y^{\prime} \in A$ such that

$$
d\left(x, x^{\prime}\right)=d\left(y, y^{\prime}\right)=\operatorname{dist}(A, B) .
$$

Definition 1.10 ([17]). Let $A$ and $B$ be two non-empty subsets of metric space $(X, d)$.

(i) A sequence $\left\{x_{n}\right\}$ in $A \cup B$, with $x_{2 n} \in A$ and $x_{2 n+1} \in B$ for $n \geqslant 0$, is said to be cyclical Cauchy sequence if for every $\epsilon>0$ there exists an $N \in \mathbb{N}$ such that $d\left(x_{n}, x_{m}\right)<\operatorname{dist}(A, B)+\epsilon$, whenever $n$ is even, $m$ is odd and $n, m \geqslant N$.

(ii) A pair $(A, B)$ is proximally complete if every cyclically Cauchy sequence $\left\{x_{n}\right\}$ in $A \cup B$, the sequences $\left\{x_{2 n}\right\}$ and $\left\{x_{2 n+1}\right\}$ have convergent subsequences in $A$ and $B$, respectively. 
Lemma 1.11 ([17]). Every cyclical Cauchy sequence is bounded.

Remark 1.12 ([42]).

(1) If $\operatorname{dist}(A, B)=0$, then cyclical Cauchy sequence in $A \cup B$ is Cauchy sequence.

(2) The cyclical Cauchy sequences may have more than one limit point.

(3) If $A$ and $B$ are closed subsets of a metric space with $\operatorname{dist}(A, B)=0$, then $(A, B)$ is proximally complete pair.

(4) Every bounded compact pair of subsets of a metric space is proximally complete.

(5) Any non-empty, closed, and convex pair in uniformly Banach space is proximally complete.

Definition 1.13 ([39]). Let $(X, d)$ be a metric space, $T: X \rightarrow X$ be a mapping, and $\epsilon>0$ be a given real number. A point $x_{0} \in X$ is said to be an $\epsilon$-fixed point (approximate fixed point) of $T$, if

$$
\mathrm{d}\left(\mathrm{x}_{0}, \mathrm{~T} x_{0}\right)<\epsilon .
$$

The set of all $\epsilon$-fixed points of $T$ is denoted by $F_{\epsilon}(T)$.

Definition 1.14 ([31]). Let $(X, d)$ be a metric space and $T: X \rightarrow X$ be a mapping. We say that $T$ has the approximate fixed point property if for all $\epsilon>0$, there exists an $\epsilon$-fixed point of $T$, that is, for all $\epsilon>0$

$$
\mathrm{F}_{\epsilon}(\mathrm{T}) \neq \emptyset \text {. }
$$

Definition 1.15 ([14]). A self-mapping $T$ on metric space $(X, d)$ is said to be asymptotically regular at a point $x \in X$ if

$$
\lim _{n \rightarrow \infty} d\left(T^{n} x, T^{n+1} x\right)=0,
$$

where $T^{n} x$ denotes the $n$-th iterate of $T$ at $x$.

Lemma $1.16([32])$. Let $(X, d)$ be a metric space and $\mathrm{T}: \mathrm{X} \rightarrow \mathrm{X}$ be an asymptotically regular at a point $\mathrm{x} \in \mathrm{X}$, then $\mathrm{T}$ has the approximate fixed point property.

\section{Main results}

We start this section by defining the following:

Definition 2.1. Let $\mathcal{T}: X \rightarrow 2^{X}$ be a multivalued map on metric space $(X, d)$ and $\alpha: X \times X \rightarrow[0,+\infty)$ be a function. Then $\mathcal{T}$ is called a multivalued $\alpha$-orbital admissible mapping if for $x \in \mathcal{X}$ and $u \in \mathcal{T} x$ following holds:

$$
\alpha(x, u) \geqslant 1 \text { implies that } \alpha(u, v) \geqslant 1 \text { for all } v \in T u \text {. }
$$

Definition 2.2. Let $\mathcal{T}: X \rightarrow 2^{x}$ be a multivalued map on a metric space and $\alpha: X \times X \rightarrow[0,+\infty)$ be a function. Then $\mathcal{T}$ is called a multivalued triangular $\alpha$-orbital admissible mapping if for $x, y \in X$ following hold:

(O1) $\mathcal{T}$ is multivalued $\alpha$-orbital admissible;

(O2) $\alpha(x, y) \geqslant 1$ and $\alpha(y, u) \geqslant 1$ implies that $\alpha(x, u) \geqslant 1$ for all $u \in T y$. 
Remark 2.3. Every generalized $\alpha_{*}$-admissible mapping is multivalued $\alpha$-orbital admissible mapping but every multivalued $\alpha$-orbital admissible mapping need not to be generalized $\alpha_{*}$-admissible mapping as shown in example below.

Example 2.4. Let $X=\{0,1,2,3\}$ with $\mathrm{d}(z, y)=|z-y|$, then $(X, \mathrm{~d})$ is a metric space. Let $\mathcal{T}: X \rightarrow 2^{X}$ and $\alpha: X \times X \rightarrow[0, \infty)$ be such that

$$
\mathcal{T} x= \begin{cases}\{1,3\}, & \text { if } x=0, \\ \{1,2\}, & \text { if } x \in\{1,2\} \\ \{3\}, & \text { if } x=3,\end{cases}
$$

and

$$
\alpha(x, y)= \begin{cases}2, & \text { if }(x, y) \in\{(0,1),(0,2),(0,3),(1,1),(1,2),(1,3),(2,1),(2,2),(2,3),(3,3)\} \\ 0, & \text { otherwise. }\end{cases}
$$

Then $\mathcal{T}$ is multivalued $\alpha$-orbital admissible. Indeed,

Case 1: $x=0 . \mathcal{T} x=\{1,3\}$, in this case only $\alpha(0,1)=2>1$ implies that $\alpha(1, v) \geqslant 1$ for all $v \in \mathcal{T} 1$, since $\alpha(1,1)=\alpha(1,2)=2>1$.

Case 2: $x \in\{1,2\}$. $\mathcal{T} x=\{1,2\}$, in this case $\alpha(1,1)=\alpha(1,2)=2>1$ implies that $\alpha(1, v) \geqslant 1$ for all $v \in \mathcal{T} 1$ and $\alpha(2, v) \geqslant 1$ for all $v \in \mathcal{T} 2$, since $\alpha(2,1)=\alpha(2,2)=2>1$.

Case 3: $x=3$. $\mathcal{T} x=\{3\}$, in this case $\alpha(3,3)=2>1$ implies that $\alpha(3, v) \geqslant 1$ for all $v \in \mathcal{T} 3=\{3\}$.

On the other side $\alpha(0,1)=2>1$ but $\alpha(3,1)=\alpha(3,2)=0$. This shows that $\alpha(u, v) \ngtr 1$ for all $u \in \mathcal{T} 0$ and $v \in \mathcal{T} 1$. So, Definition 1.3 does not hold for this mapping. Also, since $\alpha(x, y) \geqslant 1$, when $(x, y) \in$ $\{(0,1),(0,2),(0,3)(1,1),(1,2),(1,3),(2,1),(2,2),(2,3),(3,3)\}$, this implies that $\mathcal{T}$ is a multivalued triangular $\alpha$-orbital admissible mapping.

Lemma 2.5. Let $(X, \mathrm{~d})$ be a complete metric space and $\mathcal{T}: X \rightarrow 2^{x}$ be a multivalued triangular $\alpha$-orbital admissible mapping. Assume that there exist $\mathrm{x}_{0} \in X$ and $\mathrm{x}_{1} \in \mathcal{T} \mathrm{x}_{0}$ such that $\alpha\left(\mathrm{x}_{0}, \mathrm{x}_{1}\right) \geqslant 1$. Define a sequence $\left\{\mathrm{x}_{\mathrm{n}}\right\}$ in $X$ by $x_{n+1} \in \mathcal{T} x_{n}$. Then $\alpha\left(x_{m}, x_{n}\right) \geqslant 1$ for all $m, n \in \mathbb{N}$ with $m<n$.

Proof. Since there exist $x_{0} \in X$ and $x_{1} \in \mathcal{T} x_{0}$ such that $\alpha\left(x_{0}, x_{1}\right) \geqslant 1$, so from (O1) for $x_{2} \in \mathcal{T} x_{1}$, we get $\alpha\left(x_{1}, x_{2}\right) \geqslant 1$. Inductively, we get

$$
\alpha\left(x_{n}, x_{n+1}\right) \geqslant 1 \text {. }
$$

Suppose that $m<n$. Since $\left.\begin{array}{r}\alpha\left(x_{m}, x_{m+1}\right) \geqslant 1, \\ \alpha\left(x_{m+1}, x_{m+2}\right) \geqslant 1,\end{array}\right\}$ then from $(O 2)$, we get $\alpha\left(x_{m}, x_{m+2}\right) \geqslant 1$. Again, since $\left.\begin{array}{r}\alpha\left(x_{m}, x_{m+2}\right) \geqslant 1, \\ \alpha\left(x_{m+1}, x_{m+2}\right) \geqslant 1,\end{array}\right\}$ then from $(\mathrm{O} 2)$, we get $\alpha\left(x_{m}, x_{m+3}\right) \geqslant 1$. Recursively, we obtain $\alpha\left(x_{m}, x_{n}\right) \geqslant 1$

Firstly, we prove the following fixed point results.

Theorem 2.6. Let $(X, \mathrm{~d})$ be a complete metric space, $\alpha: X \times X \rightarrow[0,+\infty)$, and $\mathcal{T}: X \rightarrow \mathrm{K}(X)$. Assume that the following assertions hold:

(i) $\mathcal{T}$ is multivalued $\alpha$-orbital admissible mapping;

(ii) there exist $\mathrm{x}_{0} \in \mathcal{X}$ and $\mathrm{y}_{0} \in \mathcal{T} \mathrm{x}_{0}$ such that $\alpha\left(\mathrm{x}_{0}, \mathrm{y}_{0}\right) \geqslant 1$;

(iii) there exist $\mathrm{F} \in \mathfrak{F}$ and $\tau>0$ such that for all $x, y \in X$ and $\alpha(x, y) \geqslant 1$

$$
\mathrm{H}(\mathcal{T} x, \mathcal{T} y)>0 \quad \text { implies } \quad \tau+\mathrm{F}(\alpha(x, y) H(\mathcal{T} x, \mathcal{T} y)) \leqslant F(d(x, y))
$$


Then $\mathcal{T}$ has the approximate fixed point property. Moreover, if $\mathcal{T}$ is multivalued triangular $\alpha$-orbital admissible mapping and satisfy

(iv) $\mathcal{T}$ is continuous; (or) if $\left\{x_{n}\right\}$ is a sequence in $X$ with $\alpha\left(x_{n}, x_{n+1}\right) \geqslant 1$ such that $x_{n} \rightarrow x$ as $n \rightarrow \infty$, then there exists a subsequence $\left\{x_{n_{k}}\right\}$ of $\left\{x_{n}\right\}$ such that $\alpha\left(x_{n_{k}}, x\right) \geqslant 1$ for all $k$,

then $\mathcal{T}$ has a fixed point in $X$.

Proof. From hypothesis (ii), there exist $x_{0} \in X$ and $x_{1} \in \mathcal{T} x_{0}$ such that $\alpha\left(x_{0}, x_{1}\right) \geqslant 1$. Since T is multivalued $\alpha$-orbital admissible mapping, so, for a sequence $\left\{x_{n}\right\}_{n \in \mathbb{N}}$ in $X$ defined by $x_{n+1} \in T x_{n}$, we get $\alpha\left(x_{n}, x_{n+1}\right) \geqslant 1$. From closeness of $\mathcal{T} x_{1}$, we get, $0<\mathrm{D}\left(x_{1}, \mathcal{T} x_{1}\right) \leqslant H\left(\mathcal{T} x_{0}, \mathcal{T} x_{1}\right)$. From (2.1), we have

$$
\tau+F\left(\alpha\left(x_{0}, x_{1}\right) H\left(\mathcal{T} x_{0}, \mathcal{T} x_{1}\right)\right) \leqslant F\left(d\left(x_{0}, x_{1}\right)\right) .
$$

By using (F1) and (2.2), we obtain

$$
\mathrm{F}\left(\mathrm{D}\left(\mathrm{x}_{1}, \mathcal{T} x_{1}\right)\right) \leqslant \mathrm{F}\left(\mathrm{H}\left(\mathcal{T} x_{0}, \mathcal{T} x_{1}\right)\right) \leqslant \mathrm{F}\left(\alpha\left(x_{0}, x_{1}\right) \mathrm{H}\left(\mathcal{T} x_{0}, \mathcal{T} x_{1}\right)\right) \leqslant F\left(\mathrm{~d}\left(x_{0}, x_{1}\right)\right)-\tau .
$$

Since $\mathcal{T} x_{1}$ is compact, there exists $x_{2} \in \mathcal{T} x_{1}$ such that $d\left(x_{2}, x_{1}\right)=D\left(x_{1}, \mathcal{T} x_{1}\right)$, so (2.3) implies

$$
F\left(d\left(x_{2}, x_{1}\right)\right) \leqslant F\left(d\left(x_{1}, x_{0}\right)\right)-\tau .
$$

Recursively, we obtain a sequence $\left\{x_{n}\right\}$ in $X$ such that $x_{n+1} \in \mathcal{T} x_{n}$ and

$$
F\left(d\left(x_{n+1}, x_{n}\right)\right) \leqslant F\left(d\left(x_{n}, x_{n-1}\right)\right)-\tau
$$

for all $n \in \mathbb{N}$. Put $a_{n}=d\left(x_{n+1}, x_{n}\right)$ for $n \in \mathbb{N}$, by using (2.4), we have

$$
F\left(a_{n}\right) \leqslant F\left(a_{0}\right)-n \tau .
$$

Letting limit as $n \rightarrow \infty$ and using $\left(F 2^{*}\right)$, we obtain $a_{n}=d\left(x_{n+1}, x_{n}\right) \rightarrow 0$. Thus, $\mathcal{T}$ is asymptotically regular at $x_{0}$, so by using Lemma 1.16 , we conclude that $\mathcal{T}$ has the approximate fixed point property.

Now we prove that $\left\{x_{n}\right\}$ is a Cauchy sequence. On contrary, suppose that $\left\{x_{n}\right\}$ is not Cauchy. Then by Proposition 1.6, there exists $\gamma \in(0, \infty) \backslash \Delta(F)$ such that $F$ is continuous at $\gamma$ and for every $q \geqslant 0$, we have $n, m \in \mathbb{N}$ with $n>m \geqslant q$ and $d\left(x_{m}, x_{n}\right)>\gamma$. Also there exists $q_{0} \in \mathbb{N}$ such that

$$
a_{q_{0}}=d\left(x_{n-1}, x_{n}\right)<\gamma \text { for all } n \geqslant q_{0} .
$$

Consider two partial subsequences $x_{n_{k}}$ and $x_{m_{k}}$ of $x_{n}$ such that

$$
q_{0} \leqslant n_{k}<m_{k}<m_{k+1} \text { and } d\left(x_{m_{k}}, x_{n_{k}}\right)>\gamma \quad \text { for all } k .
$$

Observe that

$$
d\left(x_{m_{k-1}}, x_{n_{k}}\right) \leqslant \gamma \text { for all } k,
$$

where $m_{k}$ is chosen as a least number $m \in\left\{n_{k}, n_{k+1}, n_{k+2}, \ldots\right\}$ such that (2.6) is satisfied. Also note that because of (2.5) and (2.6), the case $n_{k}+1 \leqslant m_{k}$ is impossible. Thus, $n_{k}+2 \leqslant m_{k}$ for all $k$. It implies that

$$
n_{k}+1<m_{k}<m_{k}+1 \quad \text { for all } k .
$$

By (2.6), (2.7) and triangular inequality, we have for all $k$

$$
\gamma<d\left(x_{m_{k}}, x_{n_{k}}\right) \leqslant d\left(x_{m_{k}}, x_{m_{k}-1}\right)+d\left(x_{m_{k}-1}, x_{n_{k}}\right) \leqslant a_{m_{k}}+\gamma .
$$

By letting $k \rightarrow \infty$, we get 


$$
\mathrm{d}\left(\mathrm{x}_{\mathrm{m}_{\mathrm{k}}}, \mathrm{x}_{\mathrm{n}_{\mathrm{k}}}\right) \rightarrow \gamma
$$

Again by using triangular inequality together with (2.8), we have

$$
d\left(x_{m_{k}}, x_{n_{k}}\right)-a_{m_{k}+1}-a_{n_{k}+1} \leqslant d\left(x_{m_{k}+1}, x_{n_{k}+1}\right) \leqslant a_{m_{k}+1}+d\left(x_{m_{k}}, x_{n_{k}}\right)+a_{n_{k}+1},
$$

by letting $k \rightarrow \infty$, we get

$$
\mathrm{d}\left(\mathrm{x}_{\mathrm{m}_{\mathrm{k}}+1}, \mathrm{x}_{\mathrm{n}_{\mathrm{k}}+1}\right) \rightarrow \gamma
$$

Moreover, since $\mathrm{T}$ is multivalued triangular $\alpha$-orbital admissible, so by using Lemma 2.5 , we have

$$
\alpha\left(x_{m_{k}}, x_{n_{k}}\right) \geqslant 1 .
$$

From (2.1) with (F1), we get

$0 \leqslant F\left(D\left(x_{m_{k}+1}, \mathcal{T} x_{n_{k}}\right)\right) \leqslant F\left(H\left(\mathcal{T} x_{m_{k}}, \mathcal{T} x_{n_{k}}\right)\right) \leqslant F\left(\alpha\left(x_{m_{k}}, x_{n_{k}}\right) H\left(\mathcal{T} x_{m_{k}}, \mathcal{T} x_{n_{k}}\right)\right) \leqslant F\left(d\left(x_{m_{k}}, x_{n_{k}}\right)\right)-\tau$.

Compactness of $\mathcal{T} x_{\mathfrak{n}_{k}}$ gives,

$$
d\left(x_{m_{k}+1}, x_{n_{k}+1}\right) \leqslant F\left(d\left(x_{m_{k}}, x_{n_{k}}\right)\right)-\tau .
$$

By letting limit $k \rightarrow \infty$ and using (2.9), (2.10), and the fact that $F$ is continuous at $\gamma$, we obtain $\tau \leqslant 0$, which is a contradiction. Thus, $\left\{x_{n}\right\}$ is a Cauchy sequence. Since $X$ is a complete space, there exists $u \in X$ such that $\lim _{n \rightarrow \infty} x_{n}=u$. Now we discuss two cases.

Case I. If $\mathcal{T}$ is continuous.

Since $x_{n+1} \in \mathcal{T} x_{n}$, so we have

$$
\lim _{n \rightarrow \infty} D\left(x_{n+1}, \mathcal{T u}\right) \leqslant \lim _{n \rightarrow \infty} H\left(\mathcal{T} x_{n}, \mathcal{T u}\right)=0 .
$$

This shows that $u \in \mathcal{T} u$, that is, $u$ is a fixed point of $\mathcal{T}$ in $X$.

Case II. For a sequence $\left\{x_{n}\right\}$ in $X$ with $\alpha\left(x_{n}, x_{n+1}\right) \geqslant 1$ such that $x_{n} \rightarrow u$ as $n \rightarrow \infty$, then there exists a subsequence $\left\{x_{n_{k}}\right\}$ of $\left\{x_{n}\right\}$ such that $\alpha\left(x_{n_{k}}, u\right) \geqslant 1$ for all $k$.

From (2.1), we get

$$
F\left(D\left(x_{n_{k}+1}, \mathcal{T} u\right)\right) \leqslant F\left(H\left(\mathcal{T} x_{n_{k}}, \mathcal{T} u\right)\right) \leqslant F\left(\alpha\left(x_{n_{k}}, u\right) H\left(\mathcal{T} x_{n_{k}}, \mathcal{T} u\right)\right) \leqslant F\left(d\left(x_{n_{k}}, u\right)\right),
$$

which implies due to (F1) that

$$
\mathrm{D}\left(\mathrm{x}_{\mathrm{n}_{\mathrm{k}}+1}, \mathcal{T} \mathrm{u}\right) \leqslant \mathrm{d}\left(\mathrm{x}_{\mathrm{n}_{\mathrm{k}}}, \mathrm{u}\right) .
$$

Letting limit $k \rightarrow \infty$ in (2.11), we obtain $\mathrm{D}(\mathfrak{u}, \mathcal{T} u)=0$. This completes the proof.

Following Altun et al. [7], we state fixed point result for the multivalued mapping $\mathcal{T}: X \rightarrow \mathrm{CB}(X)$ by adding the following condition on $\mathrm{F}$.

(F4) $\mathrm{F}(\inf \mathcal{A})=\inf \mathrm{F}(\mathcal{A})$ for all $\mathcal{A} \subseteq(0, \infty)$ with $\inf \mathcal{A}>0$.

Theorem 2.7. Let $(X, \mathrm{~d})$ be a complete metric space and $\mathcal{T}: X \rightarrow \mathrm{CB}(X)$ satisfies all conditions of Theorem 2.6. Assume that, $\mathrm{F}$ also satisfies (F4). Then $\mathcal{T}$ has a fixed point in $X$.

Proof. From hypothesis (ii), there exist $x_{0} \in X$ and $x_{1} \in \mathcal{T} x_{0}$ such that $\alpha\left(x_{0}, x_{1}\right) \geqslant 1$. Since $T$ is multivalued $\alpha$-orbital admissible mapping, so, for a sequence $\left\{x_{n}\right\}_{n \in \mathbb{N}}$ in $X$ defined by $x_{n+1} \in T x_{n}$, we get $\alpha\left(x_{n}, x_{n+1}\right) \geqslant 1$. If $x_{1} \in \mathcal{T} x_{1}$, then $x_{1}$ is a fixed point of $\mathcal{T}$ and it completes the proof. Suppose $x_{1} \notin \mathcal{T} x_{1}$, 
then $\mathrm{D}\left(x_{1}, \mathcal{T} x_{1}\right)>0$. From closeness of $\mathcal{T} x_{1}$, we get, $0<\mathrm{D}\left(x_{1}, \mathcal{T} x_{1}\right) \leqslant H\left(\mathcal{T} x_{0}, \mathcal{T} x_{1}\right)$. From (2.1), we have

$$
\tau+\mathrm{F}\left(\alpha\left(x_{0}, x_{1}\right) H\left(\mathcal{T} x_{0}, \mathcal{T} x_{1}\right)\right) \leqslant F\left(d\left(x_{0}, x_{1}\right)\right) .
$$

By using (F1) and (2.12), we obtain

$$
F\left(D\left(x_{1}, \mathcal{T} x_{1}\right)\right) \leqslant F\left(H\left(\mathcal{T} x_{0}, \mathcal{T} x_{1}\right)\right) \leqslant F\left(\alpha\left(x_{0}, x_{1}\right) H\left(\mathcal{T} x_{0}, \mathcal{T} x_{1}\right)\right) \leqslant F\left(d\left(x_{0}, x_{1}\right)\right)-\tau .
$$

Due to (F4), we obtain

$$
F\left(D\left(x_{1}, \mathcal{T} x_{1}\right)\right)=\inf _{y \in \mathcal{T} x} F\left(d\left(x_{1}, y\right)\right)
$$

and from (2.13), we have

$$
\inf _{y \in \mathcal{T} x} F\left(d\left(x_{1}, y\right)\right) \leqslant F\left(d\left(x_{0}, x_{1}\right)\right)-\tau \leqslant F\left(d\left(x_{0}, x_{1}\right)\right)-\frac{\tau}{2} .
$$

Then, by (2.14), there exists $x_{2} \in \mathcal{T} x$ such that

$$
F\left(d\left(x_{1}, x_{2}\right)\right) \leqslant F\left(d\left(x_{0}, x_{1}\right)\right)-\frac{\tau}{2}
$$

If $x_{2} \in \mathcal{T} x_{2}$, then we have done. Otherwise, we can find $x_{3} \in \mathcal{T} x_{2}$ such that

$$
F\left(d\left(x_{2}, x_{3}\right)\right) \leqslant F\left(d\left(x_{1}, x_{2}\right)\right)-\frac{\tau}{2}
$$

Inductively, we get a sequence $\left\{x_{n}\right\}$ in $X$ such that $x_{n+1} \in \mathcal{T} x_{n}$ for all $n \in \mathbb{N}$ and

$$
F\left(d\left(x_{n}, x_{n+1}\right)\right) \leqslant F\left(d\left(x_{n_{1}}, x_{n}\right)\right)-\frac{\tau}{2} .
$$

The rest of the proof can be completed as in Theorem 2.6.

Remark 2.8. Theorem 2.6 is proper generalization of Theorem 2.2 of [7] and Theorem 2.7 is proper generalization of Theorem 2.5 of [7].

Definition 2.9. Let $A$ and $B$ be nonempty subsets of a metric space $(X, d)$. A mapping $\mathcal{T}: A \cup B \rightarrow$ $\mathrm{CB}(\mathrm{A} \cup \mathrm{B})$ is said to be multivalued cyclic $\alpha$-F-contraction if $\mathcal{T}(A) \subseteq B, \mathcal{T}(B) \subseteq A$ and there exist $F \in \mathfrak{F}$, $\alpha: X \times X \rightarrow[0,+\infty)$, and $\tau>0$ such that for all $x, y \in A \cup B$ with $\alpha(x, y) \geqslant 1$

$$
\tau+F\left(\alpha(x, y) H^{*}(\mathcal{T} x, \mathcal{T} y)\right) \leqslant F\left(d^{*}(x, y)\right)
$$

provided that $H(\mathcal{T} x, \mathcal{T} y)>\operatorname{dist}(A, B)$ and $d(x, y)>\operatorname{dist}(A, B)$.

Lemma 2.10. Let $\mathrm{A}$ and $\mathrm{B}$ be nonempty subsets of a complete metric space $(X, \mathrm{~d})$ and $\mathcal{T}: \mathrm{A} \cup \mathrm{B} \rightarrow \mathrm{K}(\mathrm{A} \cup \mathrm{B})$ be multivalued cyclic $\alpha$-F-contraction. If $\mathcal{T}$ is multivalued $\alpha$-orbital admissible mapping and there exist $x_{0} \in A$ and $y_{0} \in \mathcal{T} x_{0}$ such that $\alpha\left(x_{0}, y_{0}\right) \geqslant 1$, then, for any $x_{0} \in A \cup B, d\left(x_{n}, x_{n+1}\right) \rightarrow \operatorname{dist}(A, B)$ as $n \rightarrow \infty$, where $\left\{x_{n}\right\}$ is a sequence in $\mathrm{A} \cup \mathrm{B}$ defined by $\mathrm{x}_{\mathrm{n}+1} \in \mathcal{T} x_{\mathrm{n}}$ for each $\mathrm{n} \geqslant 0$.

Proof. If $\operatorname{dist}(A, B)=0$, then from (2.15), we have

$$
\tau+F(\alpha(x, y) H(\mathcal{T} x, \mathcal{T} y)) \leqslant F(d(x, y))
$$

By Theorem 2.6, $\mathcal{T}$ has the approximate fixed point property and $d\left(x_{n}, x_{n+1}\right) \rightarrow 0=\operatorname{dist}(A, B)$ as $n \rightarrow \infty$. Suppose that $\operatorname{dist}(A, B)>0$, then by hypothesis there exist $x_{0} \in A$ and $x_{1} \in \mathcal{T} x_{0}$ such that $\alpha\left(x_{0}, x_{1}\right) \geqslant 1$. If $\mathrm{H}\left(\mathcal{T} x_{0}, \mathcal{T} x_{1}\right) \leqslant \operatorname{dist}(A, B)$, then $\mathrm{D}\left(x_{1}, \mathcal{T} x_{1}\right) \leqslant \operatorname{dist}(A, B)$, that is contradiction to (1.1) because $\mathcal{T} x_{1} \subseteq A$. By 
similar reason, considering $d\left(x_{0}, x_{1}\right) \leqslant \operatorname{dist}(A, B)$ leads to contradiction. So, $H\left(\mathcal{T} x_{0}, \mathcal{T} x_{1}\right)>\operatorname{dist}(A, B)$ and $d\left(x_{0}, x_{1}\right)>\operatorname{dist}(A, B)$. From (2.15), we have

$$
\tau+\mathrm{F}\left(\alpha\left(\mathrm{x}_{0}, \mathrm{x}_{1}\right) \mathrm{H}^{*}\left(\mathcal{T} \mathrm{x}_{0}, \mathcal{T} \mathrm{x}_{1}\right)\right) \leqslant \mathrm{F}\left(\mathrm{d}^{*}\left(\mathrm{x}_{0}, \mathrm{x}_{1}\right)\right) .
$$

Since $\mathrm{D}\left(\mathrm{x}_{1}, \mathcal{T} x_{1}\right) \leqslant H\left(\mathcal{T} x_{0}, \mathcal{T} x_{1}\right)$, so, $\mathrm{D}^{*}\left(\mathrm{x}_{1}, \mathcal{T} x_{1}\right) \leqslant \mathrm{H}^{*}\left(\mathcal{T} x_{0}, \mathcal{T} x_{1}\right)$. By using (F1) and (2.16), we obtain

$$
\mathrm{F}\left(\mathrm{D}^{*}\left(\mathrm{x}_{1}, \mathcal{T} \mathrm{x}_{1}\right)\right) \leqslant \mathrm{F}\left(\mathrm{H}^{*}\left(\mathcal{T} x_{0}, \mathcal{T} x_{1}\right)\right) \leqslant \mathrm{F}\left(\alpha\left(x_{0}, x_{1}\right) H^{*}\left(\mathcal{T} x_{0}, \mathcal{T} x_{1}\right)\right) \leqslant F\left(d^{*}\left(x_{0}, x_{1}\right)\right)-\tau
$$

Since $\mathcal{T} x_{1}$ is compact, there exists $x_{2} \in \mathcal{T} x_{1}$ such that $d\left(x_{2}, x_{1}\right)=D\left(x_{1}, \mathcal{T} x_{1}\right)$, so (2.17) implies

$$
\mathrm{F}\left(\mathrm{d}^{*}\left(\mathrm{x}_{2}, \mathrm{x}_{1}\right)\right) \leqslant \mathrm{F}\left(\mathrm{d}^{*}\left(\mathrm{x}_{1}, \mathrm{x}_{0}\right)\right)-\tau .
$$

Since $\mathcal{T}$ is multivalued $\alpha$-orbital admissible mapping, so recursively, we obtain a sequence $\left\{x_{n}\right\}$ in $A \cup B$ such that $x_{n+1} \in \mathcal{T} x_{n}, \alpha\left(x_{n}, x_{n+1}\right) \geqslant 1$ and

$$
F\left(d^{*}\left(x_{n+1}, x_{n}\right)\right) \leqslant F\left(d^{*}\left(x_{n}, x_{n-1}\right)\right)-\tau
$$

for all $n=1,2,3, \ldots$ Put $b_{n}=d^{*}\left(x_{n+1}, x_{n}\right)$ for $n=0,1,2,3, \ldots$, by using (2.18), we have

$$
F\left(b_{n}\right) \leqslant F\left(b_{0}\right)-n \tau \text {. }
$$

Letting limit as $n \rightarrow \infty$ and using (F2), we obtain $b_{n}=d^{*}\left(x_{n+1}, x_{n}\right) \rightarrow 0$. Hence $d\left(x_{n+1}, x_{n}\right) \rightarrow \operatorname{dist}(A, B)$ as $n \rightarrow \infty$.

Lemma 2.11. Let $\mathrm{A}$ and $\mathrm{B}$ be nonempty subsets of a complete metric space $(X, \mathrm{~d})$ and $\mathcal{T}: \mathrm{A} \cup \mathrm{B} \rightarrow \mathrm{K}(X)$ be multivalued cyclic $\alpha$-F-contraction. If $\mathcal{T}$ is multivalued $\alpha$-orbital admissible mapping and there exist $x_{0} \in A$ and $y_{0} \in \mathcal{T} x_{0}$ such that $\alpha\left(x_{0}, y_{0}\right) \geqslant 1$, then the sequence $\left\{x_{n}\right\}$ in $A \cup B$ defined by $x_{n+1} \in \mathcal{T} x_{n}$ for each $n \geqslant 0$ is bounded.

Proof. From hypothesis there exist $x_{0} \in A$ and $x_{1} \in \mathcal{T} x_{0}$ such that $\alpha\left(x_{0}, x_{1}\right) \geqslant 1$. As proof of Lemma 2.10, we get a sequence $\left\{x_{n}\right\}$ in $A \cup B$ such that $x_{n+1} \in \mathcal{T} x_{0}$ with $\alpha\left(x_{n}, x_{n+1}\right) \geqslant 1$ and

$$
F\left(b_{n}\right) \leqslant F\left(b_{0}\right)-n \tau,
$$

where $b_{n}=d^{*}\left(x_{n}, x_{n+1}\right)$ for $n=0,1,2,3, \ldots$ First, we show that the sequence $\left\{x_{2 n}\right\}$ is bounded. Suppose on contrary, then there exists $p \in \mathbb{N}$ satisfying $N<d^{*}\left(x_{2 n}, x_{2(n+p)+1}\right)$ and $d^{*}\left(x_{2 n}, x_{2(n+p)-1}\right) \leqslant N$, where $N=2 p \operatorname{dist}(A, B)$. Thus, for any $n \in \mathbb{N}$, we have

$$
\begin{aligned}
N<d^{*}\left(x_{2 n}, x_{2(n+p)+1}\right) & =d\left(x_{2 n}, x_{2(n+p)+1}\right)-\operatorname{dist}(A, B) \\
& \leqslant b_{2 n}+b_{2 n+1}+\cdots+b_{2(n+p)}+(2 p-1) \operatorname{dist}(A, B) .
\end{aligned}
$$

Letting $n \rightarrow \infty$ and by using Lemma 2.10, we get

$$
N<(2 p-1) \operatorname{dist}(A, B)=N-\operatorname{dist}(A, B),
$$

which gives a contradiction. Similarly, we can prove that the sequence $\left\{x_{2 n+1}\right\}$ is also bounded. Thus, $\left\{x_{n}\right\}$ is bounded.

Remark 2.12. Consider $\mathcal{T}: A \cup B \rightarrow C B(A \cup B)$ is a multivalued cyclic $\alpha$-F-contraction, then Lemmas 2.10 and 2.11 remain true if $F$ also satisfies $(F 4)$.

Theorem 2.13. Let $(\mathrm{A}, \mathrm{B})$ be proximally complete pair of non-empty closed subsets in a metric space $(X, \mathrm{~d})$ and $\mathcal{T}: \mathrm{A} \cup \mathrm{B} \rightarrow \mathrm{K}(\mathrm{A} \cup \mathrm{B})$ be multivalued cyclic $\alpha$-F-contraction. Assume that $\mathcal{T}$ is multivalued triangular $\alpha$-orbital admissible mapping, let there exist $\mathrm{x}_{0} \in A$ and $\mathrm{y}_{0} \in \mathcal{T} x_{0}$ such that $\alpha\left(\mathrm{x}_{0}, \mathrm{y}_{0}\right) \geqslant 1$ and satisfy 
$(H)$ if $\left\{x_{n}\right\}$ is a sequence in $A \cup B$ with $\alpha\left(x_{n}, x_{n+1}\right) \geqslant 1$ such that $x_{n} \rightarrow x$ as $n \rightarrow \infty$, then there exists a subsequence $\left\{x_{n_{k}}\right\}$ of $\left\{x_{n}\right\}$ such that $\alpha\left(x_{n_{k}}, x\right) \geqslant 1$ for all $k$.

Then there exists $(x, y) \in A \times B$ such that $D(x, \mathcal{T} x)=\operatorname{dist}(A, B)$ and $D(y, \mathcal{T} y)=\operatorname{dist}(A, B)$ with $d(x, y)=$ $\operatorname{dist}(A, B)$.

Proof. Let $x_{0} \in A$ and $x_{1} \in \mathcal{T} x_{0}$ such that $\alpha\left(x_{0}, x_{1}\right) \geqslant 1$, then as proof of Lemma 2.10, we get a sequence $\left\{x_{n}\right\}$ in $A \cup B$ such that $x_{n+1} \in \mathcal{T} x_{0}$ with $\alpha\left(x_{n}, x_{n+1}\right) \geqslant 1$ and

$$
F\left(b_{n}\right) \leqslant F\left(b_{0}\right)-n \tau
$$

where $b_{n}=d^{*}\left(x_{n}, x_{n+1}\right)$ for $n=0,1,2,3, \ldots$ From Lemma 2.11, we have $\left\{x_{n}\right\}$ is bounded.

Now we prove that $\left\{x_{n}\right\}$ is cyclical Cauchy sequence in $A \cup B$. Since $\mathcal{T}$ is multivalued triangular $\alpha$ orbital admissible mapping, so by Lemma 2.5 , we have $\alpha\left(x_{n}, x_{m}\right) \geqslant 1$ for any $m, n \in \mathbb{N}$ with $m \geqslant n$. Then by (2.15), we obtain

$$
F\left(d^{*}\left(x_{2 n}, x_{2 m+1}\right)\right) \leqslant F\left(d^{*}\left(x_{0}, x_{2(m-n)+1}\right)\right)-(2 n) \tau .
$$

Letting $n \rightarrow \infty$, we get $F\left(d^{*}\left(x_{2 n}, x_{2 m+1}\right)\right) \rightarrow-\infty$, so by $\left(F 2^{*}\right)$, we get $d^{*}\left(x_{2 n}, x_{2 m+1}\right) \rightarrow 0$ as $n \rightarrow \infty$. Therefore, $d\left(x_{2 n}, x_{2 m+1}\right) \rightarrow \operatorname{dist}(A, B)$ as $n \rightarrow \infty$, which implies that the $\left\{x_{n}\right\}$ is cyclical Cauchy sequence in $A \cup B$. Since the pair $(A, B)$ is proximally complete, we have, the sequences $\left\{x_{2 n}\right\}$ and $\left\{x_{2 n+1}\right\}$ have convergent subsequence. Let $\left\{x_{2 n_{k}}\right\}$ be a subsequence of $\left\{x_{2 n}\right\}$ such that $x_{2 n_{k}} \rightarrow x$ as $n \rightarrow \infty$ for some $x \in A$. Note that for all $k \geqslant 1$

$$
\operatorname{dist}(A, B) \leqslant d\left(x, x_{2 n_{k}-1}\right) \leqslant d\left(x, x_{2 n_{k}}\right)+d\left(x_{2 n_{k}}, x_{2 n_{k}-1}\right) .
$$

Letting $k \rightarrow \infty$ in (2.19) and using Lemma 2.10, we get

$$
\lim _{k \rightarrow \infty} d\left(x, x_{2 n_{k}-1}\right)=\operatorname{dist}(A, B) .
$$

From (2.15), for all $x, y \in A \cup B$ with $H^{*}(\mathcal{T} x, \mathcal{T} y)>0$ and $\alpha(x, y) \geqslant 1$, we get

$$
H^{*}(\mathcal{T} x, \mathcal{T} y) \leqslant d^{*}(x, y)
$$

From hypothesis $(H)$, there exists a subsequence $\left\{x_{2 n_{k q}}\right\}$ of $\left\{x_{2 n_{k}}\right\}$ such that $\alpha\left(x_{2 n_{k q}}, x_{2 n_{k}}\right) \geqslant 1$, then from (2.21), we obtain

$$
\mathrm{D}^{*}\left(\mathrm{x}_{2 \mathrm{n}_{\mathrm{kq}}}, \mathcal{T} x\right) \leqslant \mathrm{H}^{*}\left(\mathcal{T} x_{2 \mathrm{n}_{\mathrm{kq}}-1}, \mathcal{T} x\right) \leqslant \mathrm{d}^{*}\left(\mathrm{x}_{2 \mathrm{n}_{\mathrm{kq}}-1}, x\right) .
$$

Letting $k \rightarrow \infty$ in (2.22) and using (2.20), we get $D^{*}(x, \mathcal{T} x)=0$. Consequently, $D(x, \mathcal{T} x)=\operatorname{dist}(A, B)$. Similarly, if $\left\{x_{2 n_{k}+1}\right\}$ is a subsequence of $\left\{x_{2 n+1}\right\}$ that converges to $y \in B$, we can prove that $D(y, \mathcal{T} y)=$ $\operatorname{dist}(A, B)$. Moreover,

$$
d(x, y)=\lim _{k \rightarrow \infty} d\left(x_{2 n_{k}}, x_{2 n_{k}+1}\right)=\operatorname{dist}(A, B)
$$

As similar arguments in Theorem 2.13, we state the following.

Theorem 2.14. Let $(A, B)$ be proximally complete pair of non-empty closed subsets in a metric space $(X, d)$ and $\mathcal{T}: \mathrm{A} \cup \mathrm{B} \rightarrow \mathrm{CB}(\mathrm{A} \cup \mathrm{B})$ be multivalued cyclic $\alpha$-F-contraction satisfying all conditions of Theorem 2.13 with $\mathrm{F}$ satisfying condition $(\mathrm{F} 4)$. Then there exists $(x, y) \in A \times B$ such that $\mathrm{D}(x, \mathcal{T} x)=\operatorname{dist}(\mathrm{A}, \mathrm{B})$ and $\mathrm{D}(\mathrm{y}, \mathcal{T} y)=$ $\operatorname{dist}(A, B)$ with $d(x, y)=\operatorname{dist}(A, B)$. 
Example 2.15. Let $X=\left\{\frac{1}{2^{n-1}}: n \in \mathbb{N}\right\} \cup\{0\}$ with usual metric d. Let

$$
A=\left\{\frac{1}{2^{2 n-1}}: n \in \mathbb{N}\right\} \cup\{0,1\} \text { and } B=\left\{\frac{1}{2^{2 n}}: n \in \mathbb{N}\right\} \cup\{0,1\} .
$$

Then $\operatorname{dist}(A, B)=0$ and clearly $(A, B)$ is proximally complete pair. Define $\mathcal{T}: A \cup B \rightarrow K(A \cup B), \alpha$ : $X \times X \rightarrow[0,+\infty)$ and $\mathrm{F}: \mathbb{R}^{+} \rightarrow \mathbb{R}$ by

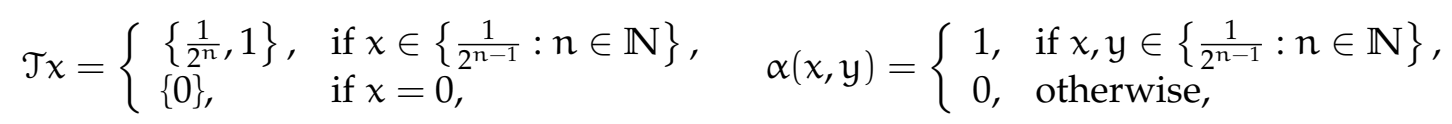

and $F(r)=\ln r$. Then $F \in \mathfrak{F}, \mathcal{T}(A) \subseteq B$ and $\mathcal{T}(B) \subseteq A$. Since $\alpha(x, y) \geqslant 1$ when $x, y \in\left\{\frac{1}{2^{n-1}}: n \in \mathbb{N}\right\}$, so, $\mathcal{T}$ is multivalued triangular $\alpha$-orbital admissible. Note that $\alpha(x, y) \geqslant 1$ with $d(T x, T y)>\operatorname{dist}(A, B)=0$, when $x=\frac{1}{2^{n}}$ and $y=\frac{1}{2^{m}}$ such that $m>n \geqslant 1$. Let $x=\frac{1}{2^{n}}$ and $y=\frac{1}{2^{m}}$ such that $m>n \geqslant 1$, then $\mathrm{d}^{*}(x, y)=\left|\frac{2^{\mathrm{m}-\mathfrak{n}}-1}{2^{\mathrm{m}}}\right|$ and $\mathrm{H}^{*}(\mathcal{T} x, \mathcal{T} y)=\left|\frac{2^{\mathrm{m}-\mathfrak{n}}-1}{2^{\mathrm{m}+1}}\right|$. This implies that

$$
F\left(\alpha(x, y) H^{*}(\mathcal{T} x, \mathcal{T} y)\right)-F\left(d^{*}(x, y)\right)=\ln \left|\frac{2^{m-n}-1}{2^{m+1}}\right|-\ln \left|\frac{2^{m-n}-1}{2^{m}}\right|=\ln \left|\frac{1}{2}\right|<-\frac{1}{2} .
$$

Therefore, $\mathcal{T}$ is multivalued cyclic $\alpha$-F-contraction for $\tau=\frac{1}{2}$. Hence all conditions of Theorem 2.13 are satisfied. Moreover, we have $1 \in A$ and $1 \in B$ such that

$$
\mathrm{D}(1, \mathcal{T} 1)=0=\operatorname{dist}(\mathrm{A}, \mathrm{B}) \text { and } \mathrm{d}(1,1)=0=\operatorname{dist}(\mathrm{A}, \mathrm{B}) .
$$

By taking $\alpha(x, y)=1$ in Theorem 2.13 and Theorem 2.14, respectively, we get the following:

Corollary 2.16. Let $(\mathrm{A}, \mathrm{B})$ be proximally complete pair of non-empty closed subsets in a metric space $(X, \mathrm{~d})$ and $\mathcal{T}: A \cup B \rightarrow K(A \cup B)$ be a mapping such that $\mathcal{T}(A) \subseteq B$ and $\mathcal{T}(B) \subseteq A$. If there exists $F \in \mathfrak{F}$ and $\tau>0$ such that for all $x, y \in A \cup B$ we have

$$
\tau+F\left(H^{*}(\mathcal{T} x, \mathcal{T} y)\right) \leqslant F\left(d^{*}(x, y)\right)
$$

provided that $\mathrm{H}(\mathrm{Tx}, \mathrm{Ty})>\operatorname{dist}(\mathrm{A}, \mathrm{B})$ and $\mathrm{d}(\mathrm{x}, \mathrm{y})>\operatorname{dist}(\mathrm{A}, \mathrm{B})$, then there exists $(x, y) \in A \times B$ such that $D(x, \mathcal{T} x)=\operatorname{dist}(A, B)$ and $D(y, \mathcal{T} y)=\operatorname{dist}(A, B)$ with $d(x, y)=\operatorname{dist}(A, B)$.

Corollary 2.17. Let $(\mathrm{A}, \mathrm{B})$ be proximally complete pair of non-empty closed subsets in a metric space $(X, \mathrm{~d})$ and $\mathcal{T}: A \cup B \rightarrow C B(A \cup B)$ be a cyclic mapping satisfying all conditions of Corollary 2.16 with $\mathrm{F}$ satisfying condition (F4). Then there exists $(x, y) \in A \times B$ such that $D(x, \mathcal{T} x)=\operatorname{dist}(A, B)$ and $D(y, \mathcal{T} y)=\operatorname{dist}(A, B)$ with $d(x, y)=\operatorname{dist}(A, B)$.

Considering $F(r)=\ln r$, Corollary 2.16 and Corollary 2.17 imply the followings respectively.

Corollary 2.18. Let $(\mathrm{A}, \mathrm{B})$ be proximally complete pair of non-empty closed subsets in a metric space $(X, \mathrm{~d})$ and $\mathcal{T}: \mathrm{A} \cup \mathrm{B} \rightarrow \mathrm{K}(\mathrm{A} \cup \mathrm{B})$ be a mapping satisfying

$$
\mathrm{H}(\mathcal{T} x, \mathcal{T} y) \leqslant k d(x, y)+(1-k) \operatorname{dist}(A, B),
$$

where $\mathrm{k} \in(0,1)$ with $\mathcal{T}(A) \subseteq B$ and $\mathcal{T}(B) \subseteq A$. Then there exists $(x, y) \in A \times B$ such that $D(x, \mathcal{T} x)=\operatorname{dist}(A, B)$ and $\mathrm{D}(\mathrm{y}, \mathcal{T} y)=\operatorname{dist}(\mathrm{A}, \mathrm{B})$ with $\mathrm{d}(\mathrm{x}, \mathrm{y})=\operatorname{dist}(\mathrm{A}, \mathrm{B})$.

Corollary 2.19. Let $(\mathrm{A}, \mathrm{B})$ be proximally complete pair of non-empty closed subsets in a metric space $(X, \mathrm{~d})$ and $\mathcal{T}: A \cup B \rightarrow C B(A \cup B)$ be a mapping satisfying all conditions of Corollary 2.18 with $\mathrm{F}$ satisfying condition (F4). Then there exists $(x, y) \in A \times B$ such that $D(x, \mathcal{T} x)=\operatorname{dist}(A, B)$ and $D(y, \mathcal{T} y)=\operatorname{dist}(A, B)$ with $d(x, y)=$ $\operatorname{dist}(A, B)$. 
Taking $F(r)=-\frac{1}{\sqrt{r}}$ in Corollary 2.16 and Corollary 2.17, we get special cases of nonlinear contraction $[13,38]$.

Corollary 2.20. Let $(A, B)$ be proximally complete pair of non-empty closed subsets in a metric space $(X, d)$ and $\mathcal{T}: \mathrm{A} \cup \mathrm{B} \rightarrow \mathrm{K}(\mathrm{A} \cup \mathrm{B})$ be a mapping such that $\mathcal{T}(\mathrm{A}) \subseteq \mathrm{B}$ and $\mathcal{T}(\mathrm{B}) \subseteq \mathrm{A}$ and for all $\mathrm{x}, \mathrm{y} \in \mathrm{A} \cup \mathrm{B}$ satisfies

$$
H^{*}(\mathcal{T} x, \mathcal{T} y) \leqslant \frac{1}{\left(1+\tau \sqrt{d^{*}(x, y)}\right)^{2}} d^{*}(x, y)
$$

provided that $\mathrm{H}(\mathrm{T} x, \mathrm{Ty})>\operatorname{dist}(\mathrm{A}, \mathrm{B})$ and $\mathrm{d}(\mathrm{x}, \mathrm{y})>\operatorname{dist}(\mathrm{A}, \mathrm{B})$. Then there exists $(x, y) \in A \times B$ such that $\mathrm{D}(x, \mathcal{T} x)=\operatorname{dist}(A, B)$ and $\mathrm{D}(\mathrm{y}, \mathcal{T} y)=\operatorname{dist}(A, B)$ with $\mathrm{d}(x, y)=\operatorname{dist}(A, B)$.

Corollary 2.21. Let $(\mathrm{A}, \mathrm{B})$ be proximally complete pair of non-empty closed subsets in a metric space $(X, \mathrm{~d})$ and $\mathcal{T}: \mathrm{A} \cup \mathrm{B} \rightarrow \mathrm{CB}(\mathrm{A} \cup \mathrm{B})$ be a mapping satisfying all conditions of Corollary 2.20 with $\mathrm{F}$ satisfying condition (F4). Then there exists $(x, y) \in A \times B$ such that $D(x, \mathcal{T} x)=\operatorname{dist}(A, B)$ and $D(y, \mathcal{T} y)=\operatorname{dist}(A, B)$ with $d(x, y)=$ $\operatorname{dist}(A, B)$.

\section{Best proximity results in partially ordered metric space}

Let $(X, \mathrm{~d}, \preceq)$ be a partially ordered metric space and $\mathcal{T}: X \rightarrow 2^{X}$ be a multivalued mapping. For $A, B \in 2^{x}, A \preceq B$ implies that $a \preceq b$ for all $a \in A$ and $b \in B$. We say that $\mathcal{T}$ is monotone increasing if $\mathcal{T} x \preceq \mathcal{T} y$ for all $x, y \in X$, for which $x \preceq y$. The existence of best proximity points in the setting of partially ordered metric space is discussed by many authors (see $[2,10,33]$ and references therein). There are many applications in differential and integral equations of monotone mappings in ordered metric spaces. In this section, we derive the following new results in partially ordered metric spaces from our main results.

Theorem 3.1. Let $(X, \mathrm{~d}, \preceq)$ be a complete partially ordered metric space and $\mathcal{T}: X \rightarrow \mathrm{K}(X)$. Assume that the following assertions hold:

(i) $\mathcal{T}$ is monotone increasing;

(ii) there exist $x_{0} \in X$ and $y_{0} \in \mathcal{T} x_{0}$ such that $x_{0} \preceq y_{0}$;

(iii) there exist $\mathrm{F} \in \mathfrak{F}$ and $\tau>0$ such that for all $\mathrm{x}, \mathrm{y} \in \mathcal{X}$ with $\mathrm{x} \preceq \mathrm{y}$

$$
\mathrm{H}(\mathcal{T} x, \mathcal{T} y)>0 \quad \text { implies } \quad \tau+\mathrm{F}(\mathrm{H}(\mathcal{T} x, \mathcal{T} y)) \leqslant \mathrm{F}(\mathrm{d}(x, y))
$$

(iv) $\mathcal{T}$ is continuous; (or) if $\left\{x_{n}\right\}$ is a sequence in $X$ with $x_{n} \preceq x_{n+1}$ such that $x_{n} \rightarrow x$ as $n \rightarrow \infty$, then there exists a subsequence $\left\{x_{n_{k}}\right\}$ of $\left\{x_{n}\right\}$ such that $x_{n_{k}} \preceq x$ for all $k$.

Then $\mathcal{T}$ has a fixed point in $X$.

Proof. Define $\alpha: X \times X \rightarrow[0, \infty)$ by

$$
\alpha(x, y)= \begin{cases}1, & x \preceq y \\ 0, & \text { otherwise }\end{cases}
$$

then for $z, y \in X$ with $z \preceq y$ and $\alpha(z, y) \geqslant 1$, we get $\mathcal{T}$ is multivalued triangular $\alpha$-orbital admissible mapping. Also, suppose that $\alpha(x, y) \geqslant 1$ and $H(\mathcal{T} x, \mathcal{T} y)>0$, then $x \leqslant y$ and hypothesis (iii) implies

$$
\tau+\mathrm{F}(\alpha(x, y) H(\mathcal{T} x, \mathcal{T} y))=\tau+F(H(\mathcal{T} x, \mathcal{T} y)) \leqslant F(d(x, y))
$$

Thus, all the conditions of Theorem 2.6 hold true. Hence, $\mathcal{T}$ has a fixed point in $X$.

By similar arguments as in Theorem 3.1, from Theorem 2.7, Theorem 2.13 and Theorem 2.14, we state the following. 
Theorem 3.2. Let $(X, \mathrm{~d}, \preceq)$ be a complete partially ordered metric space and $\mathcal{T}: X \rightarrow \mathrm{CB}(X)$ satisfies all conditions of Theorem 3.1. Assume that, $\mathrm{F}$ also satisfies (F4). Then $\mathcal{T}$ has a fixed point in $X$.

Theorem 3.3. Let $(A, B)$ be proximally complete pair of non-empty closed subsets in a partially ordered metric space $(X, \mathrm{~d}, \preceq)$ and $\mathcal{T}: \mathrm{A} \cup \mathrm{B} \rightarrow \mathrm{K}(\mathrm{A} \cup \mathrm{B})$ be mapping such that $\mathcal{T}(\mathrm{A}) \subseteq \mathrm{B}, \mathcal{T}(\mathrm{B}) \subseteq \mathrm{A}$ and satisfying the following assertions:

(i) $\mathcal{T}$ is monotone increasing;

(ii) there exist $x_{0} \in X$ and $y_{0} \in \mathcal{T} x_{0}$ such that $x_{0} \preceq y_{0}$;

(iii) if $\left\{x_{n}\right\}$ is a sequence in $A \cup B$ with $x_{n} \preceq x_{n+1}$ such that $x_{n} \rightarrow x$ as $n \rightarrow \infty$, then there exists a subsequence $\left\{x_{n_{k}}\right\}$ of $\left\{x_{n}\right\}$ such that $x_{n_{k}} \preceq x$ for all $k$;

(iv) there exist $F \in \mathfrak{F}$ and $\tau>0$ such that for all $x, y \in A \cup B$ with $x \preceq y$

$$
H(\mathcal{T} x, \mathcal{T} y)>\operatorname{dist}(A, B) \& \operatorname{dist}(A, B) \text { implies } \tau+F\left(H^{*}(\mathcal{T} x, \mathcal{T} y)\right) \leqslant F\left(d^{*}(x, y)\right)
$$

Then there exists $(x, y) \in A \times B$ such that $D(x, \mathcal{T} x)=\operatorname{dist}(A, B)$ and $D(y, \mathcal{T} y)=\operatorname{dist}(A, B)$ with $d(x, y)=$ $\operatorname{dist}(A, B)$.

Theorem 3.4. Let $(A, B)$ be proximally complete pair of non-empty closed subsets in a partially ordered metric space $(X, \mathrm{~d}, \preceq)$ and $\mathcal{T}: \mathrm{A} \cup \mathrm{B} \rightarrow \mathrm{CB}(\mathrm{A} \cup \mathrm{B})$ be multivalued cyclic mapping satisfying all conditions of Theorem 3.3 with $\mathrm{F}$ satisfying condition (F4). Then there exists $(x, y) \in A \times B$ such that $D(x, \mathcal{T} x)=\operatorname{dist}(A, B)$ and $\mathrm{D}(\mathrm{y}, \mathcal{T} y)=\operatorname{dist}(A, B)$ with $\mathrm{d}(x, y)=\operatorname{dist}(A, B)$.

Considering $F(r)=\ln r$, Theorem 3.3 and Theorem 3.4 imply the followings respectively.

Corollary 3.5. Let (A, B) be proximally complete pair of non-empty closed subsets in a partially ordered metric space $(X, \mathrm{~d}, \preceq)$ and $\mathcal{T}: \mathrm{A} \cup \mathrm{B} \rightarrow \mathrm{K}(\mathrm{A} \cup \mathrm{B})$ be a mapping satisfying hypotheses (i)-(iii) of Theorem 3.3. Assume that, for $x \preceq y$,

$$
H(\mathcal{T} x, \mathcal{T} y) \leqslant k d(x, y)+(1-k) \operatorname{dist}(A, B),
$$

where $\mathrm{k} \in(0,1)$. Then there exists $(x, y) \in A \times B$ such that $D(x, \mathcal{T} x)=\operatorname{dist}(A, B)$ and $D(y, \mathcal{T} y)=\operatorname{dist}(A, B)$ with $\mathrm{d}(x, y)=\operatorname{dist}(A, B)$.

Corollary 3.6. Let (A, B) be proximally complete pair of non-empty closed subsets in a partially ordered metric space $(X, \mathrm{~d}, \preceq)$ and $\mathcal{T}: \mathrm{A} \cup \mathrm{B} \rightarrow \mathrm{CB}(\mathrm{A} \cup \mathrm{B})$ be a mapping satisfying all conditions of Corollary 3.5 with $\mathrm{F}$ satisfying condition (F4). Then there exists $(x, y) \in A \times B$ such that $\mathrm{D}(x, \mathcal{T} x)=\operatorname{dist}(A, B)$ and $\mathrm{D}(\mathrm{y}, \mathcal{T} y)=\operatorname{dist}(A, B)$ with $d(x, y)=\operatorname{dist}(A, B)$.

\section{Application to single-valued mappings}

In this section, as an application of our previous sections, we obtain best proximity point results and fixed point results for single-valued mappings.

Theorem 4.1. Let $(X, \mathrm{~d})$ be a complete metric space, $\alpha: X \times X \rightarrow[0,+\infty)$, and $\mathcal{T}$ be a self-mapping on $X$. Assume that the following assertions hold:

(i) $\mathcal{T}$ is $\alpha$-orbital admissible mapping;

(ii) there exist $\mathrm{x}_{0} \in X$ and $\mathrm{y}_{0}=\mathrm{T} \mathrm{x}_{0}$ such that $\alpha\left(\mathrm{x}_{0}, \mathrm{y}_{0}\right) \geqslant 1$;

(iii) there exist $F \in \mathfrak{F}$ and $\tau>0$ such that for all $x, y \in X$ and $\alpha(x, y) \geqslant 1$

$$
\mathrm{d}(\mathcal{T} x, \mathcal{T} y)>0 \quad \text { implies } \quad \tau+\mathrm{F}(\alpha(x, y) d(\mathcal{T} x, \mathcal{T} y)) \leqslant \mathrm{F}(\mathrm{d}(x, y))
$$

Then $\mathcal{T}$ has the approximate fixed point property. Moreover, if $\mathcal{T}$ is triangular $\alpha$-orbital admissible mapping and satisfies 
(iv) $\mathcal{T}$ is continuous; (or) if $\left\{x_{n}\right\}$ is a sequence in $X$ with $\alpha\left(x_{n}, x_{n+1}\right) \geqslant 1$ such that $x_{n} \rightarrow x$ as $n \rightarrow \infty$, then there exists a subsequence $\left\{x_{n_{k}}\right\}$ of $\left\{x_{n}\right\}$ such that $\alpha\left(x_{n_{k}}, x\right) \geqslant 1$ for all $k$,

then $\mathcal{T}$ has a fixed point in $X$.

Proof. Define a mapping $\mathrm{f}: X \rightarrow \mathrm{K}(X)$ by $\mathrm{f}(\mathrm{x})=\{\mathcal{T} x\}$ for all $x \in X$. Continuity of $\mathcal{T}$ implies continuity of $\mathrm{f}$. Suppose that for $x \in X$ and $u \in f x=\{\mathcal{T} x\}, \alpha(x, u) \geqslant 1$. This implies $\alpha(x, \mathcal{T} x) \geqslant 1$. By hypothesis (i), we get $\alpha\left(T x, T^{2} x\right) \geqslant 1$. Also, for $x, y \in X$ with $\alpha(x, y) \geqslant 1$ and $\alpha(y, u) \geqslant 1$ for all $u \in f(y)=\{\mathcal{T} y\}$ hypothesis (i) implies $\alpha(x, \mathcal{T} y)=\alpha(x, u) \geqslant 1$.

Let $H(f x, f y)>0$ for $x, y \in X$, then $d(\mathcal{T} x, \mathcal{T} y)>0$. From hypothesis (iii), we get

$$
\tau+F(\alpha(x, y) H(f x, f y))=\tau+F(\alpha(x, y) d(\mathcal{T} x, \mathcal{T} y)) \leqslant F(d(x, y))
$$

Hence, $f$ is multivalued $\alpha$-orbital admissible mapping. Hence all conditions of Theorem 2.6 hold true and $f$ has a fixed point $x^{*}$ in $X$. Then $x^{*} \in f\left(x^{*}\right)=\left\{\mathcal{T} x^{*}\right\}$. This implies $x^{*}=\mathcal{T} x^{*}$, that is $\mathcal{T}$ has a fixed point in $x$.

Remark 4.2. Corollary 3.11 of [20] is for $\alpha$-type F-contraction, which is obtained by Theorem 3.8 and Theorem 3.9 of [20], whose proofs are erroneous as mentioned by Imdad et al. [27]. While, in Theorem 4.1, we prove fixed point result for $\alpha$-type F-contraction without any ambiguity which generalizes Theorem 1.5 .

Definition 4.3. Let $A$ and $B$ be nonempty subsets of a metric space $(\mathcal{X}, d)$. A mapping $\mathcal{T}: A \cup B \rightarrow A \cup B$ is said to be cyclic $\alpha$-F-contraction if $\mathcal{T}(A) \subseteq B, \mathcal{T}(B) \subseteq A$ and there exists $F \in \mathfrak{F}, \alpha: \mathcal{X} \times \mathcal{X} \rightarrow[0,+\infty)$ and $\tau>0$ such that for all $x, y \in A \cup B$ with $\alpha(x, y) \geqslant 1$

$$
\tau+F\left(\alpha(x, y) d^{*}(\mathcal{T} x, \mathcal{T} y)\right) \leqslant F\left(d^{*}(x, y)\right)
$$

provided that $d(\mathcal{T} x, \mathcal{T} y)>\operatorname{dist}(A, B)$ and $d(x, y)>\operatorname{dist}(A, B)$.

By similar arguments as in Theorem 4.1, we state the following.

Theorem 4.4. Let $(\mathrm{A}, \mathrm{B})$ be proximally complete pair of non-empty closed subsets in a metric space $(X, \mathrm{~d})$ and $\mathcal{T}: A \cup B \rightarrow A \cup B$ be a cyclic $\alpha$-F-contraction. Assume that $\mathcal{T}$ is triangular $\alpha$-orbital admissible mapping, there exist $x_{0} \in A$ and $y_{0}=T x_{0}$ such that $\alpha\left(x_{0}, y_{0}\right) \geqslant 1$ and satisfy condition $(H)$. Then there exists $(x, y) \in A \times B$ such that $\mathrm{d}(\mathrm{x}, \mathcal{T} x)=\operatorname{dist}(\mathrm{A}, \mathrm{B})$ and $\mathrm{d}(\mathrm{y}, \mathcal{T} y)=\operatorname{dist}(\mathrm{A}, \mathrm{B})$ with $\mathrm{d}(\mathrm{x}, \mathrm{y})=\operatorname{dist}(\mathrm{A}, \mathrm{B})$.

Corollary 4.5. Let $(\mathrm{A}, \mathrm{B})$ be proximally complete pair of non-empty closed subsets in a metric space $(X, \mathrm{~d})$ and $\mathcal{T}: A \cup B \rightarrow A \cup B$ be a mapping satisfying

$$
\mathrm{d}(\mathcal{T} x, \mathcal{T} y) \leqslant k d(x, y)+(1-k) \operatorname{dist}(A, B),
$$

where $\mathrm{k} \in(0,1)$ with $\mathcal{T}(\mathrm{A}) \subseteq \mathrm{B}$ and $\mathcal{T}(\mathrm{B}) \subseteq \mathrm{A}$. Then there exists $(x, y) \in \mathrm{A} \times \mathrm{B}$ such that $\mathrm{d}(\mathrm{x}, \mathcal{T} x)=\operatorname{dist}(\mathrm{A}, \mathrm{B})$ and $\mathrm{d}(\mathrm{y}, \mathcal{T} y)=\operatorname{dist}(A, B)$ with $\mathrm{d}(\mathrm{x}, \mathrm{y})=\operatorname{dist}(\mathrm{A}, \mathrm{B})$.

Corollary 4.6 ([16, Theorem 3.4]). Let $\mathrm{A}$ and $\mathrm{B}$ be nonempty closed subsets of a complete metric space $(X, \mathrm{~d})$ and $\mathcal{T}: A \cup B \rightarrow A \cup B$ be a mapping satisfying

$$
\mathrm{d}(\mathcal{T} x, \mathcal{T} y) \leqslant k d(x, y)+(1-k) \operatorname{dist}(A, B),
$$

where $\mathrm{k} \in(0,1)$ with $\mathcal{T}(\mathrm{A}) \subseteq \mathrm{B}$ and $\mathcal{T}(\mathrm{B}) \subseteq \mathrm{A}$. If either $\mathrm{A}$ or $\mathrm{B}$ is bounded compact, then there exists $\mathrm{x} \in \mathrm{A} \cup \mathrm{B}$ such that $\mathrm{d}(x, \mathcal{T} x)=\operatorname{dist}(A, B)$.

Example 4.7. Let $X=\mathbb{R}^{2}$ with metric $d\left(x, x^{\prime}\right)=\left|x_{1}-x_{2}\right|+\left|y_{1}-y_{2}\right|$ for all $x=\left(x_{1}, y_{1}\right), x^{\prime}=\left(x_{2}, y_{2}\right) \in X$. Let

$$
A=\{(-1,1),(1,1),(0,2)\}
$$

and

$$
B=\{(-4, v):-4 \leqslant v \leqslant 0\} \cup\{(4, v):-4 \leqslant v \leqslant 0\} \cup\{(u, v):-4<u<4, v=-4\} .
$$

Then $\operatorname{dist}(A, B)=4$ and clearly $(A, B)$ is proximally complete pair. Define $\mathcal{T}: A \cup B \rightarrow K(A \cup B), \alpha$ : 
$X \times X \rightarrow[0,+\infty)$ and $\mathrm{F}: \mathbb{R}^{+} \rightarrow \mathbb{R}$ by

$$
\begin{aligned}
& \mathcal{T}(x, y)= \begin{cases}(-4,0), & \text { if }(x, y)=(-1,1), \\
(4,0), & \text { if }(x, y) \in\{(1,1),(0,2)\} \\
(-1,1), & \text { if }(x, y) \in\{(u, v):-4<u<4, v=-4\} \cup\{(-4,0)\}, \\
(1,1), & \text { if }(x, y) \in\{(4, v):-4 \leqslant v \leqslant 0\} \\
(0,2), & \text { if }(x, y) \in\{(-4, v):-4 \leqslant v \leqslant 0\} \backslash\{(-4,0)\},\end{cases} \\
& \alpha(x, y)= \begin{cases}1, & \text { if }(x, y) \in\{(1,1),(-4,-4),(4,0),(0,2)\}, \\
0, & \text { otherwise, }\end{cases}
\end{aligned}
$$

and $F(r)=\ln r$. Then $F \in \mathfrak{F}, \mathcal{T}(A) \subseteq B$ and $\mathcal{T}(B) \subseteq A$. Since $\alpha(x, y) \geqslant 1$ when $(x, y) \in\{(1,1),(-4,-4),(4,0)$, $(0,2)\}$, so, $\mathcal{T}$ is triangular $\alpha$-orbital admissible. Let $\alpha(x, y) \geqslant 1$ with $d(x, y)>\operatorname{dist}(A, B)$ and $d(T x, T y)>$ $\operatorname{dist}(A, B)$, then there arises two cases, when $x=(1,1), y=(-4,-4)$ and $x=(-4,-4), y=(0,2)$. In both cases, $d^{*}(x, y)=6$ and $d^{*}(T x, T y)=2$, this implies

$$
F(\alpha(x, y) d(T x, T y))-F(d(x, y))=F(2)-F(6)=\ln \left(\frac{1}{3}\right)<-\frac{1}{3} .
$$

Hence $T$ is cyclic $\alpha$-F-contraction with $\tau=\frac{1}{3}$. Thus, all conditions of Theorem 4.4 hold true. Moreover, we have $(-1,1) \in A$ and $(-4,0) \in B$ such that

$$
\begin{aligned}
& \mathrm{d}((-1,1), \mathrm{T}(-1,1))=4=\operatorname{dist}(\mathrm{A}, \mathrm{B}), \\
& \mathrm{d}((-4,0), \mathrm{T}(-4,0))=4=\operatorname{dist}(\mathrm{A}, \mathrm{B})
\end{aligned}
$$

and

$$
\mathrm{d}((-1,1),(-4,0))=4=\operatorname{dist}(\mathrm{A}, \mathrm{B}) .
$$

Observe that, for $x=(-1,1), y=(4,0)$, we have

$$
\frac{d^{*}(T x, T y)}{d^{*}(x, y)}=1
$$

This shows that there exists no $k \in(0,1)$ such that $(4.1)$ holds true. Therefore, Corollary 4.6 is not applicable for this example.

Combining Theorem 2.4 of [25] with Example 2.1 of [25] gives the following corollary.

Corollary 4.8 ([25, Consequence of Theorem 2.4$])$. Let $(X, \mathrm{~d}, \preceq)$ be partially ordered metric space. Assume that the following assertions hold true:

(i) $\mathcal{T}$ is non-decreasing and ordered GF-contraction;

(ii) there exists $x_{0} \in X$ such that $x_{0} \preceq \mathcal{T} x_{0}$;

(iii) either for a given $x \in X$ and a sequence $\left\{x_{n}\right\}$ with $x_{n} \preceq x_{n+1}$ such that $x_{n} \rightarrow x$ as $n \rightarrow \infty$, we have $\mathcal{T} x_{n} \rightarrow \mathcal{T} x$; or if $\left\{x_{n}\right\}$ is a sequence in $X$ with $x_{n} \preceq x_{n+1}$ such that $x_{n} \rightarrow x$ as $n \rightarrow \infty$, then either $\mathcal{T} x_{n} \preceq x$, or $\mathcal{T}^{2} x_{\mathrm{n}} \preceq \mathrm{x}$ holds for all $\mathrm{n} \in \mathbb{N}$.

Then $\mathcal{T}$ has a fixed point in $X$.

Theorem 4.9. Let $(\mathrm{A}, \mathrm{B})$ be proximally complete pair of non-empty closed subsets in a partially ordered metric space $(X, \mathrm{~d}, \preceq)$ and $\mathcal{T}: A \cup B \rightarrow A \cup B$ be a mapping satisfying the following assertions:

(i) $\mathcal{T}(\mathrm{A}) \subseteq \mathrm{B}$ and $\mathcal{T}(\mathrm{B}) \subseteq \mathrm{A}$;

(ii) $\mathcal{T}$ is monotone increasing;

(iii) there exist $\mathrm{x}_{0} \in X$ and $\mathrm{y}_{0}=\mathcal{T} \mathrm{x}_{0}$ such that $\mathrm{x}_{0} \preceq \mathrm{y}_{0}$; 
(iv) if $\left\{x_{n}\right\}$ is a sequence in $A \cup B$ with $x_{n} \preceq x_{n+1}$ such that $x_{n} \rightarrow x$ as $n \rightarrow \infty$, then there exists a subsequence $\left\{x_{n_{k}}\right\}$ of $\left\{x_{n}\right\}$ such that $x_{n_{k}} \preceq x$ for all $k$;

(v) there exists $\mathrm{F} \in \mathfrak{F}$ and $\tau>0$ such that for all $\mathrm{x}, \mathrm{y} \in \mathrm{A} \cup \mathrm{B}$ with $\mathrm{x} \preceq \mathrm{y}$

$$
d(\mathcal{T} x, \mathcal{T} y)>\operatorname{dist}(A, B), d(x, y)>\operatorname{dist}(A, B) \text { implies } \tau+F\left(d^{*}(\mathcal{T} x, \mathcal{T} y)\right) \leqslant F\left(d^{*}(x, y)\right) .
$$

Then there exists $(x, y) \in A \times B$ such that $d(x, \mathcal{T} x)=\operatorname{dist}(A, B)$ and $d(y, \mathcal{T} y)=\operatorname{dist}(A, B)$ with $d(x, y)=$ $\operatorname{dist}(A, B)$.

Corollary 4.10. Let $(X, \mathrm{~d}, \preceq)$ be a complete partially ordered metric space and $\mathcal{T}$ be a self-mapping on $X$. Assume that the following assertions hold:

(i) $\mathcal{T}$ is monotone increasing;

(ii) there exist $x_{0} \in X$ and $y_{0}=T x_{0}$ such that $x_{0} \preceq y_{0}$;

(iii) there exist $\mathrm{F} \in \mathfrak{F}$ and $\tau>0$ such that for all $\mathrm{x}, \mathrm{y} \in \mathcal{X}$ with $\mathrm{x} \preceq \mathrm{y}$

$$
\mathrm{d}(\mathcal{T} x, \mathcal{T} y)>0 \text { implies } \tau+\mathrm{F}(\mathrm{d}(\mathcal{T} x, \mathcal{T} y)) \leqslant F(d(x, y))
$$

(iv) for a given $\mathrm{x} \in X$ and a sequence $\left\{x_{n}\right\}$ with $x_{n} \preceq x_{n+1}$ such that $x_{n} \rightarrow x$ as $\mathrm{n} \rightarrow \infty$, we have $\mathcal{T} x_{n} \rightarrow \mathcal{T} x$; (or) if $\left\{x_{n}\right\}$ is a sequence in $X$ with $x_{n} \preceq x_{n+1}$ such that $x_{n} \rightarrow x$ as $n \rightarrow \infty$, then there exists a subsequence $\left\{x_{n_{k}}\right\}$ of $\left\{x_{n}\right\}$ such that $x_{n_{k}} \preceq x$ for all $k$.

Then $\mathcal{T}$ has a fixed point in $X$.

Remark 4.11. In Corollary 4.10, F needs not to satisfy (F3), while in Corollary 4.8, F satisfies (F1)-(F3). Therefore, Corollary 4.10 generalizes Corollary 4.8.

Corollary 4.12 ([34, Theorems 2.1 and 2.2]). Let $(X, \mathrm{~d}, \preceq)$ be a complete partially ordered metric space and $\mathcal{T}$ be a self-mapping on $X$. Assume that the following assertions hold:

(i) $\mathcal{T}$ is monotone increasing;

(ii) there exist $\mathrm{x}_{0} \in X$ and $\mathrm{y}_{0}=\mathrm{T} \mathrm{x}_{0}$ such that $\mathrm{x}_{0} \preceq \mathrm{y}_{0}$;

(iii) for all $x, y \in X$ with $x \preceq y, k \in(0,1)$

$$
\mathrm{d}(\mathcal{T} x, \mathcal{T} y) \leqslant k d(x, y)
$$

(iv) for a given $x \in X$ and a sequence $\left\{x_{n}\right\}$ with $x_{n} \preceq x_{n+1}$ such that $x_{n} \rightarrow x$ as $n \rightarrow \infty$, we have $\mathcal{T} x_{n} \rightarrow \mathcal{T} x$; (or) if $\left\{x_{n}\right\}$ is a sequence in $X$ with $x_{n} \preceq x_{n+1}$ such that $x_{n} \rightarrow x$ as $n \rightarrow \infty$, then there exists a subsequence $\left\{x_{n_{k}}\right\}$ of $\left\{x_{n}\right\}$ such that $x_{n_{k}} \preceq x$ for all $k$.

Then $\mathcal{T}$ has a fixed point in $X$.

Example 4.13. Consider the sequence $\left\{S_{n}\right\}_{n \in \mathbb{N}}$ as in Example 2.5 of [44]. Let $X=\left\{S_{n}: n \in \mathbb{N}\right\}$ and $\mathrm{d}(x, y)=|x-y|$ for all $x, y \in X$. Define order on $X$ as

$$
\mathrm{S}_{\mathrm{n}} \leqslant \mathrm{S}_{\mathrm{m}} \Leftrightarrow \mathrm{n} \leqslant \mathrm{m}
$$

Then $(X, d, \leqslant)$ is a complete partially ordered metric space. Define a self-mapping $\mathcal{T}$ on $X$ by

$$
\mathcal{T}\left(S_{n}\right)= \begin{cases}1, & \text { if } n=1, \\ S_{n-1}, & \text { if } n>1,\end{cases}
$$

and $F: \mathbb{R}^{+} \rightarrow \mathbb{R}$ by $F(r)=\ln r+r$, then $F \in \mathfrak{F}$. Also, $\mathcal{T}$ is monotone increasing. Indeed, let $S_{n} \preceq S_{m}$, then $n \leqslant m$, so we have three possibilities.

(i) if $\mathrm{n}=\mathrm{m}=1$, then $\mathcal{T}\left(S_{\mathrm{n}}\right)=1=\mathcal{T}\left(S_{\mathrm{m}}\right)$; 
(ii) if $n=1 \& m>1$, then $\mathcal{T}\left(S_{n}\right)=1 \leqslant S_{m-1}=\mathcal{T}\left(S_{m}\right)$;

(iii) if $n>1 \& m>1$ with $n<m$, then $\mathcal{T}\left(S_{n}\right)=S_{n-1} \leqslant S_{m-1}=\mathcal{T}\left(S_{m}\right)$.

Now, let $d\left(\mathcal{T}\left(S_{m}\right), \mathcal{T}\left(S_{n}\right)\right)>0$ and $S_{n} \leqslant S_{m}$, then there arises two cases:

Case 1. For every $m \in \mathbb{N}, m>2 \wedge n=1$,

$$
\frac{d\left(\mathcal{T}\left(S_{m}\right), \mathcal{T}\left(S_{1}\right)\right)}{d\left(S_{m}, S_{1}\right)} e^{d\left(\mathcal{T}\left(S_{m}\right), \mathcal{T}\left(S_{1}\right)\right)-d\left(S_{m}, S_{1}\right)}<e^{-1}
$$

Case 2. For every $m, n \in \mathbb{N}, m>n>1$,

$$
\frac{\mathrm{d}\left(\mathcal{T}\left(S_{\mathrm{m}}\right), \mathcal{T}\left(S_{\mathfrak{n}}\right)\right)}{\mathrm{d}\left(\mathrm{S}_{\mathrm{m}}, S_{\mathfrak{n}}\right)} e^{\mathrm{d}\left(\mathcal{T}\left(S_{\mathrm{m}}\right), \mathcal{T}\left(S_{\mathfrak{n}}\right)\right)-\mathrm{d}\left(\mathrm{S}_{\mathrm{m}}, S_{1}\right)}<e^{-1} .
$$

In both cases, $\mathcal{T}$ satisfies hypothesis (iii) of Corollary 4.10 for $\tau=1$. Thus, all conditions of Corollary 4.10 hold true and $S_{1}$ is the fixed point of $\mathcal{T}$ in $X$.

Remark 4.14. In Example 4.13, T is not Harjani-Sadarangani's type contraction [21] and also it is not a Banach's contraction because

$$
\lim _{n \rightarrow \infty} \frac{d\left(\mathcal{T}\left(S_{n}\right), \mathcal{T}\left(S_{1}\right)\right)}{d\left(S_{n}, S_{1}\right)}=1
$$

Therefore, Corollary 4.12 can not be applied for this mapping also Theorems 2 and 5 of [21] are not applicable for this mapping.

\section{Acknowledgment}

This article was funded by the Deanship of Scientific Research (DSR), King Abdulaziz University, Jeddah. Therefore, the authors acknowledge with thanks DSR, KAU for financial support.

\section{References}

[1] M. Abbas, A. Hussain, P. Kumam, A coincidence best proximity point problem in G-metric spaces, Abstr. Appl. Anal., 2015 (2015), 12 pages. 1

[2] A. Abkar, M. Gabeleh, Best proximity points for cyclic mappings in ordred metric spaces, J. Optim. Theory Appl., 150 (2011), 188-193. 1, 3

[3] A. Abkar, M. Gabeleh, The existence of best proximity points for multivalued non-self-mappings,Rev. R. Acad. Cienc. Exactas Fs. Nat. Ser. A Math. RACSAM, 107 (2013), 319-325. 1

[4] R. P. Agarwal, D. O’Regan, D. R. Sahu, Fixed Point Theory for Lipschitzian-type Mappings with Applications, Springer, New York, (2009). 1

[5] M. U. Ali, T. Kamram, W. Sintunavarat, P. Katchang, Mizoguchi-Takahashi's Fixed Point Theorem with $\alpha, \eta$ Functions, Abstr. Appl. Anal., 2013 (2013), 4 pages. 1, 1.3

[6] M. A. Al-Thagafi, N. Shahzad, Convergence and existence results for best proximity points, Nonlinear Anal., 70 (2009), 3665-3671. 1

[7] I. Altun, G. Minak, H. Dağ, Multivalued F-contractions on complete metric space, J. Nonlinear Convex Anal., 16 (2015), 659-666. 1, 2, 2.8

[8] A. Amini-Harandi, Best proximity points for proximal generalized contractions in metric spaces, Optim. Lett., 7 (2013), 913-921. 1

[9] H. J. Asl, S. Rezapour, N. Shahzad, On fixed points of $\alpha-\psi$-contractive multifunctions, Fixed Point Theory Appl., 2012 (2012), 6 pages. 1

[10] S. S. Basha, Best proximity point theorems on partially ordered sets, Optim. Lett., 7 (2013), 1035-1043. 3

[11] S. S. Basha, P. Veeramani, Best proximity pair theorems for multifunctions with open fibres, J. Approx. Theory, 103 (2000), 119-129. 1

[12] V. Berinde, M. Păcurar, The role of the Pompeiu-Hausdorff metric in fixed point theory, Creat. Math. Inform., 22 (2013), 143-150. 1

[13] D. W. Boyd, J. S. W. Wong, On nonlinear contractions, Proc. Amer. Math. Soc., 20 (1969), 458-464. 2 
[14] F. E. Browder, W. V. Petrysyn, The solution by iteration of nonlinear functional equation in Banach spaces, Bull. Amer. Math. Soc., 72 (1966), 571-575. 1.15

[15] B. S. Choudhury, P. Maity, N. Metiya, Best proximity point results in set-valued analysis, Nonlinear Anal. Model. Control, 21 (2016), 293-305. 1

[16] A. A. Eldred, P. Veeramani, Existence and convergence of best proximity points, J. Math. Anal. Appl., 323 (2006), 1001-1006. 1, 4.6

[17] R. Espínola, G. S. R. Kosuru, P. Veeramani, Pythagorean property and best proximity point theorems, J. Optim. Theory Appl., 164 (2015), 534-550. 1.8, 1.9, 1.10, 1.11

[18] K. Fan, Extensions of two fixed point theorems of F.E. Browder, Math. Z., 122 (1969), 234-240. 1

[19] M. Gabeleh, Best proximity points: Globel minimization of multivalued non-self mappings, Optim Lett., 8 (2014), 11011112. 1

[20] D. Gopal, M. Abbas, D. K. Patel, C. Vetro, Fixed points of $\alpha$-type F-contractive mappings with an application to nonlinear fractional differential equation, Acta Math. Sci., 36 (2016), 957-970. 1, 4.2

[21] J. Harjani, K. Sadarangani, Fixed point theorems for weakly contractive mappings in partially ordered sets, Nonlinear Anal., 71 (2009), 3403-3410. 4.14

[22] N. Hussain, M. A. Kutbi, P. Salimi, Fixed point theory in $\alpha$-complete metric spaces with applications, Abstr. Appl. Anal., 2014 (2014), 11 pages. 1

[23] N. Hussain, A. Latif, I. Iqbal, Fixed point results for generalized F-contractions in modular metric and fuzzy metric spaces, Fixed Point Theory Appl., 2015 (2015), 20 pages. 1

[24] N. Hussain, A. Latif, P. Salimi, Best proximity point results for modified Suzuki $\alpha$ - $\psi$-proximal contractions, Fixed Point Theory and Applications, 2014 (2014), 16 pages. 1

[25] N. Hussain, P. Salimi, Suzuki-Wardowski type fixed point theorems for $\alpha$-GF-contractions, Taiwanese J. Mathematics, 18 (2014), 1879-1895. 1, 4, 4.8

[26] N. Hussain, P. Salimi, A. Latif, Fixed point results for single and set-valued $\alpha-\eta-\psi$-contractive mappings, Fixed Point Theory Appl., 2013 (2013), 23 pages. 1.2

[27] M. Imdad, R. Gubran, M. Arif, D. Gopal, An observation on $\alpha$-type F-contractions and some ordered-theoretic fixed point results, Math. Sci., 11 (2017), 247-255. 1, 4.2

[28] I. Iqbal, N. Hussain, N. Sultana, Fixed Points of Multivalued Non-Linear F-Contractions with Application to Solution of Matrix Equations, Filomat, 31 (2017), 3319-3333. 1

[29] V. I. Istrățescu, Fixed point theory an introduction, Reidel, Dordrecht, (1981). 1

[30] E. Karapinar, H. H. Alsulami, M. Noorwali, Some extensions for Geraghty type contractive mappings, J. Inequal. Appl., 2015 (2015), 22 pages. 1

[31] U. Kohlenbach, L. Leuştean, The approximate fixed point property in product spaces, Nonlinear Anal., 66 (2007), 806818. 1.14

[32] A. Latif, W. Sintunavarat, A. Ninsri, Approximate fixed point theorems for partial generalized convex contraction mappings in $\alpha$-complete metric spaces, Taiwanese J. Math., 19 (2015), 315-333. 1.16

[33] C. Mongkolkeha, P. Kumam, Best proximity point theorems for generalized cyclic contarctions in ordered metric spaces, J. Optim. Theory Appl., 155 (2012), 215-226. 3

[34] J. J. Nieto, R. Rodriguez-López, Contractive mapping theorems in partially ordered sets and applications to ordinary differential equations, Order, 22 (2005), 223-239. 4.12

[35] M. Olgun, G. Minak, I. Altun, A new approach to Mizoguchi-Takahshi type fixed point theorems, J. Nonlinear Convex Anal., 17 (2016), 579-587. 1

[36] A. Padcharoen, D. Gopal, P. Chaipunya, P. Kumam, Fixed point and periodic point results for $\alpha$-type F-contractions in modular metric spaces, Fixed Point Theory Appl., 2016 (2016), 12 pages. 1

[37] O. Popescu, Some new fixed point theorems for $\alpha$-Geraghty contractive type maps in metric spaces, Fixed Point Theory Appl., 2014 (2014), 12 pages. 1, 1.1, 1

[38] E. Rakotch, A note on contractive mappings, Proc Am Math Soc., 13 (1962), 459-465. 2

[39] S. Reich, Approximate selections, best approximations, fixed points, and invariant sets, J. Math. Anal. Appl., 62 (1978), 104-113. 1.13

[40] P. Salimi, A. Latif, N. Hussain, Modified $\alpha-\psi$-contractive mappings with applications, Fixed Point Theory Appl., 2013 (2013), 19 pages. 1

[41] B. Samet, C. Vetro, P. Vetro, Fixed point theorem for $\alpha$-廿-contractive type mappings, Nonlinear Anal., 75 (2012), 21542165. 1

[42] S. Sanhan, C. Mongkolkeha, Convergence and best proximity points for Berinde's cyclic contraction with proximally complete property, Math. Methods Appl. Sci., 39 (2016), 4866-4873. 1, 1.12

[43] M. Turinici, Wardowski implicit contractions in metric spaces, arXiv, 2012 (2012), 8 pages. 1.6, 1, 1.7

[44] D. Wardowski, Fixed points of a new type of contractive mappings in complete metric spaces, Fixed Point Theory Appl., 2012 (2012), 6 pages. 1, 1.4, 1.5, 4.13

[45] D. Wardowski, N. Van Dung, Fixed points of F-weak contractions on complete metric space, Demonstr. Math., 47 (2014), 146-155. 1

[46] K. Wlodarczyk, R. Plebaniak, A. Banach, Best proximity points for cyclic and non-cyclic set-valued relativy quasiasymptotic contractions in uniform spaces, Nonlinear Anal., 70 (2009), 3332-3341. 1 